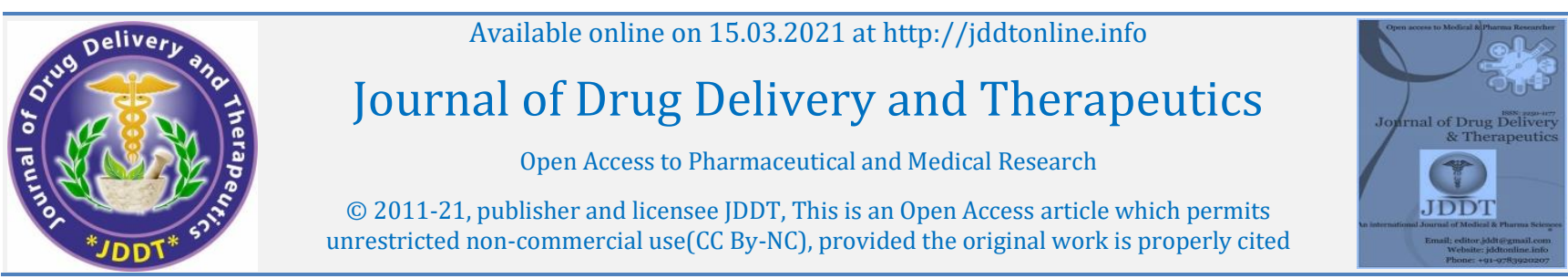

(C) 2011-21, publisher and licensee JDDT, This is an Open Access article which permits Open Access Full Text Article

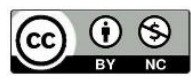

Research Article

\title{
An Overview of the Health Issues of the Elderly: A Cross Sectional Study
}

\author{
Archana Anil, * Nimmy N John, Jaya Soorya B P, H Doddaya \\ Department of Pharmacy Practice, N.E.T Pharmacy College, Raichur-584103 Karnataka, India
}

\section{Article Info:}

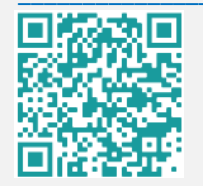

\section{Article History:}

Received 09 Jan 2021;

Review Completed 17 Feb 2021

Accepted 25 Feb 2021;

Available online 15 March 2021

Cite this article as:

Anil A, John NN, B P JS, Doddaya H, An Overview of the Health Issues of the Elderly: A Cross Sectional Study, Journal of Drug Delivery and Therapeutics. 2021; 11(2):38-41

DOI: http://dx.doi.org/10.22270/jddt.v11i2.4761

*Address for Correspondence:

Mrs. Nimmy N John, Assistant Professor, Department of Pharmacy Practice, NET Pharmacy College, Raichur- 584103, Karnataka, India

\section{Abstract}

Background: In the changing era of our community posing a challengeable situation to the senior support-needing population of the community, there is a need to know the different kinds of problems faced by the elderly. In the view of all these facts, this study was conducted to study the various health related problems among geriatrics.

Objective: To study various health related problems in elderly population.

Materials and methods: This cross-sectional study was carried out in May to August 2020 in Ernakulam district of Kerala, India. 150 elderly (aged above 60 years) were interviewed using a predesigned questionnaire.

Results: In the present study, $45.33 \%$ were males and $54.67 \%$ were females. Among the total elderly, $27.33 \%$ were illiterate, $56.00 \%$ had received primary education, and $14.00 \%$ had received secondary education while only $2.67 \%$ had received education up to the graduate level. The common health problems elderly was decreased vision (35.33\%), followed by arthritis $(13.33 \%)$, hearing problems $(12.00 \%)$, urinary problems $(8.00 \%)$, diabetes $(6.00 \%)$ weight loss (4.67\%), dental problems (4.00\%), Chronic obstructive pulmonary disease (3.33\%), Hypertension (3.00\%), asthma and anaemia with $(2.67 \%)$ each, fatty liver and cancer with $(2.00 \%)$ each and Ischemic heart disease $(0.67 \%)$.

Conclusion: The study highlights the common health problems the elderly face. In this study, it was found that the most prevalent health problem among geriatrics was vision impairment followed by arthritis and hearing impairment.

Keywords: Geriatrics; visual impairment; Health problems; Arthritis; Ageing.

\section{INTRODUCTION}

The WHO defines aging as a process of progressive change in the biological, psychological and social structure of individuals ${ }^{1}$. The elderly are, on the whole, less healthy than the non-elderly ${ }^{3}$. During the process of ageing, the impairments in anatomical and physiological lead to affect physical, mental and social wellbeing of the individuals ${ }^{4}$.

With the rise in elderly population in India, it is important to undertake studies with elderly.

According to the National council on aging, about 92 percent of elderly people have chronic disease and 77 percent of them was having atleast two. Among that heart disease, stroke, cancer and diabetes are the most common chronic diseases found in geriatric patients. In senior patients, another major problems was impairment in thinking, learning and remembering. ${ }^{5}$

In elderly people due to aging the risk of fall, impaired vision and hearing loss are common. Not only physical but also mental and emotional wellbeing is also an important factor. Without being left alone they should be encouraged to participate in recreation activities which help them to have a healthy mind and healthy life. Exercising in groups, spending time in library and engaging in leisure activities with same age people will improve their mental health and thus improves their quality of life. 6

For the elderly who stays alone undergo any surgery or major procedure recently will face a difficulty in performing their smaller daily activities. This will adversely affect their mental or emotional health. ${ }^{6}$ Majority of elderly patient thinks that the attitude of people towards elderly was neglect. A feeling of low self-esteem due to loss of earning and social recognition may cause stressful situation for elderly people. This state of mind is harmful for the patients. ${ }^{7}$

There is a need for highlighting the medical and socioeconomic problem faced by elderly patient and necessary steps should be followed for the improvement in their quality of life. Special care and attention should be given to the senior patients in performing their daily activities and proper treatment facility should be provided for the geriatric patient without any negligence. There is a need for geriatric counselling centres which will help the elderly people by taking care of their physical and psychological need.

\section{MATERIALS AND METHODS}

\section{Study design and Subjects}

A cross sectional study was conducted for a period of three months from May 2020 to August 2020 in the rural areas of Ernakulam district, Kerala. The study used a prospective 
audit of 150 elderly aged above 60 years. Patients with age less than 60 years and who are not willing to participate were excluded from the study.

\section{Participant recruitment and study method}

Permission was obtained from the ethical clearance committee before beginning of study. 150 elderly participants were included in the study after obtaining their prior consent. The data was collected by interviewing all the eligible subjects willing to participate in the study. The data was collected from elderly population by using pre predesigned questionnaire. The questionnaire was developed by reviewing related Indian studies. Elderly were asked regarding the health problems and medications they are using.

\section{RESULTS AND DISCUSSION:}

\section{RESULT:}

Table 1: Age distribution of participants $(n=150)$

\begin{tabular}{|c|c|c|c|}
\hline Sl. No & Age & Frequency & Percentage \\
\hline 1 & $60-69$ & 91 & $60.67 \%$ \\
\hline 2 & $70-79$ & 48 & $32.00 \%$ \\
\hline 3 & Above 80 & 11 & $7.33 \%$ \\
\hline
\end{tabular}

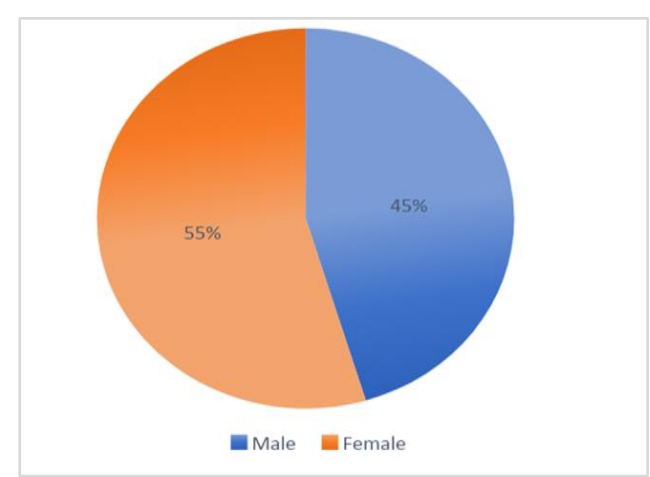

Figure 1: Gender distribution of participants

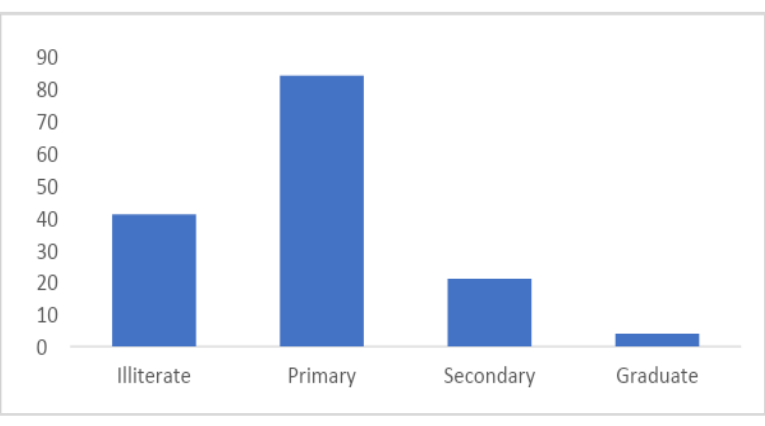

Figure 2: Educational status of participants

Table 2: Distribution of participants according to social habits

\begin{tabular}{|c|c|c|}
\hline Habits & Frequency & Percentage \\
\hline Smoking & 42 & $28.00 \%$ \\
\hline Alcohol & 17 & $11.33 \%$ \\
\hline
\end{tabular}

Table 3: Distribution of participants according to type of family $(\mathrm{N}=150)$

\begin{tabular}{|c|c|c|}
\hline Type of Family & Frequency & Percentage \\
\hline Joint & 38 & $25.33 \%$ \\
\hline Nuclear & 112 & $74.67 \%$ \\
\hline Extended & 0 & $0.00 \%$ \\
\hline
\end{tabular}

Table 4: Distribution of participants according to type of dietary pattern $(\mathrm{N}=150)$

\begin{tabular}{|c|c|c|}
\hline Type of Dietary Pattern & Frequency & Percentage \\
\hline Vegetarian & 21 & $14.00 \%$ \\
\hline Non-vegetarian & 10 & $6.67 \%$ \\
\hline Mixed & 119 & $79.33 \%$ \\
\hline
\end{tabular}

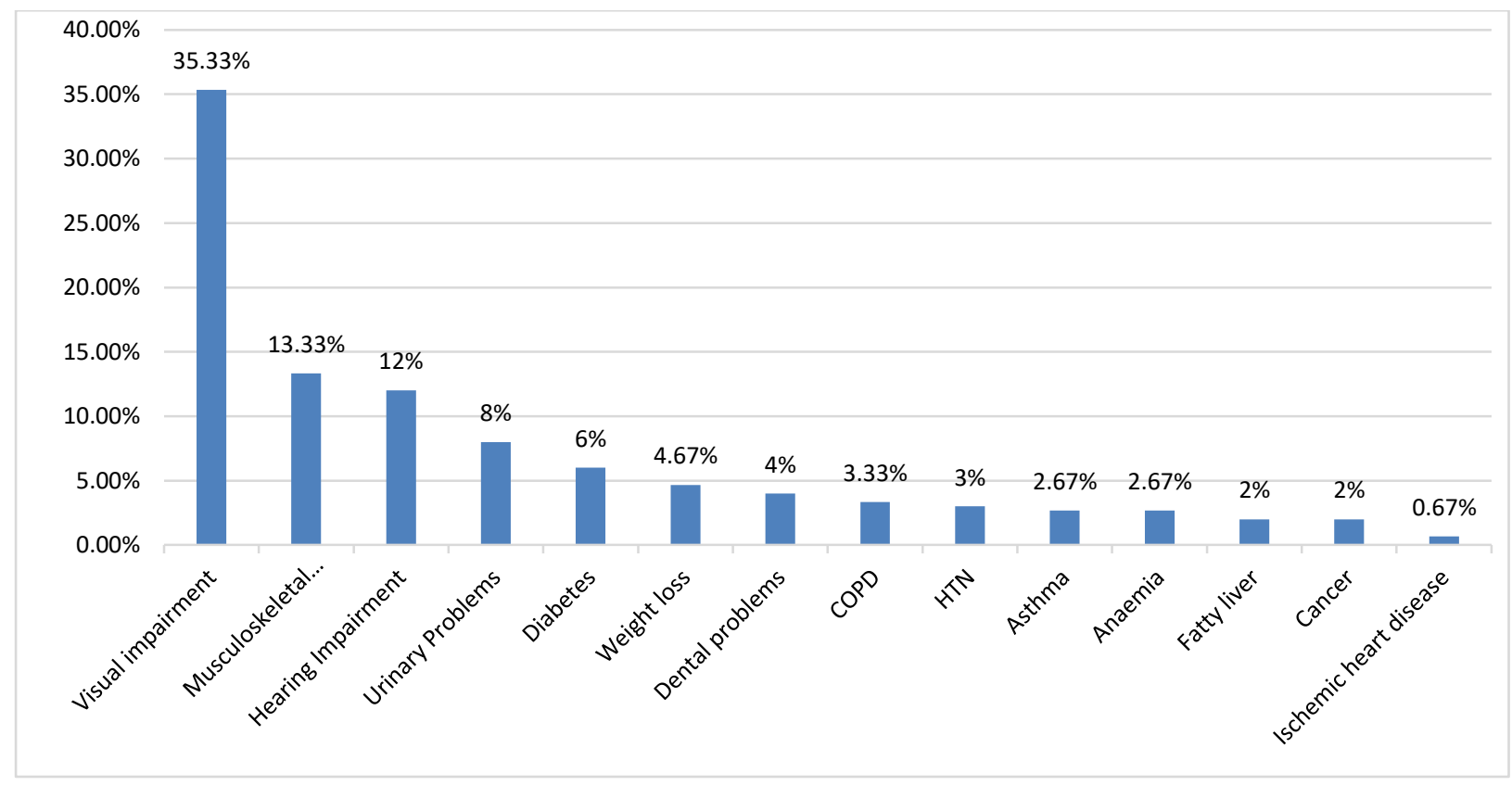

Figure 3: Distribution of participants according to health problems 
Table 5: Visual Impairment $(\mathrm{N}=53)$

\begin{tabular}{|c|c|c|}
\hline Eye Impairment & Frequency & Percentage \\
\hline Diabetic retinopathy & 08 & $15.09 \%$ \\
\hline Cataract & 10 & $6.66 \%$ \\
\hline Glaucoma & 07 & $4.66 \%$ \\
\hline Presbyopia & 12 & $8 \%$ \\
\hline $\begin{array}{c}\text { Age related macular } \\
\text { degeneration }\end{array}$ & 16 & $10.66 \%$ \\
\hline
\end{tabular}

Table 6: Musculoskeletal system $(\mathrm{N}=20)$

\begin{tabular}{|c|c|c|}
\hline $\begin{array}{c}\text { Musculoskeletal } \\
\text { Problems }\end{array}$ & Frequency & Percentage \\
\hline Arthritis & 06 & $30 \%$ \\
\hline Fracture & 03 & $15 \%$ \\
\hline Osteoporosis & 04 & $20 \%$ \\
\hline Osteoarthritis & 02 & $10 \%$ \\
\hline Low back pain & 05 & $25 \%$ \\
\hline
\end{tabular}

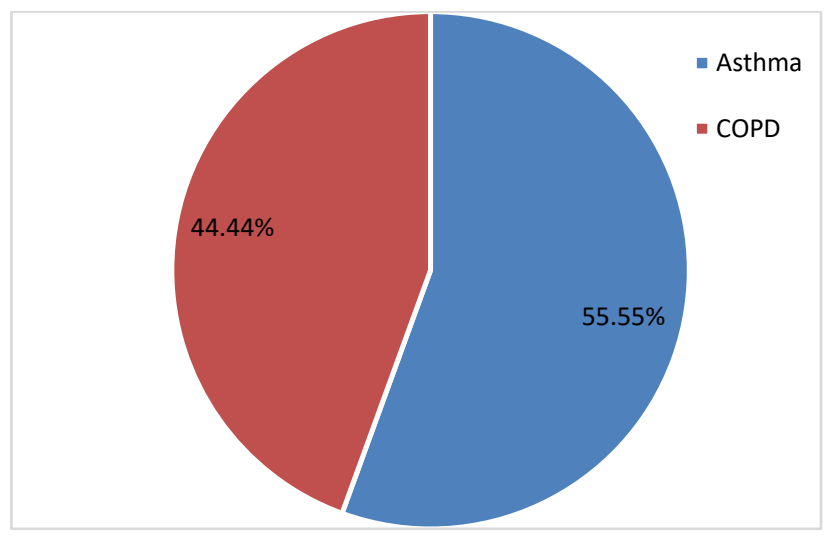

Figure 4: Respiratory problems among geriatric patient

Table 7: Lifestyle disease in geriatric patients

\begin{tabular}{|c|c|c|}
\hline Lifestyle Disease & Frequency & Percentage \\
\hline Heart disease & 1 & $0.67 \%$ \\
\hline Diabetes mellitus & 9 & $6 \%$ \\
\hline Hypertension & 5 & $3 \%$ \\
\hline Cancer & 3 & $2 \%$ \\
\hline
\end{tabular}

Table 8: ENT problems

\begin{tabular}{|c|c|c|}
\hline ENT problems & Frequency & Percentage \\
\hline Ear & 18 & $12.00 \%$ \\
\hline Nose & 0 & $0 \%$ \\
\hline Throat & 0 & $0 \%$ \\
\hline
\end{tabular}

\section{DISCUSSION:}

The elderly are a special group at high risk of losing independence and autonomy and suffering from multiple pathology and iatrogenic problems. Functional capacity can be improved through factors related to adaptability, fitness, social changes and disease prevention. With the rise in geriatric population in India, it is important that we look into various health issues encountered by them. It is important to undertake studies with elderly, results of such studies can assist the development of health policies for the elderly. In the view of all these facts, this study was conducted to study the various health related problems among geriatrics.

Among the total participants, age was taken into consideration by dividing into 3 groups. Maximum number of participants was found in the age group of 60-69(60.67\%) followed by $70-79(32.00 \%)$ and least were found in above $80(7.33 \%)$.The same is stated in Table 1. The age group characteristics were similar to the study conducted by Kulothungan $\mathrm{K}$ et al $^{8}$.

Of the total of 150 elders surveyed, $45.33 \%$ were males and $54.67 \%$ were females. This is depicted in Figure 1.

Among the total elderly, $27.33 \%$ were illiterate, $56.00 \%$ had received primary education, and $14.00 \%$ had received secondary education while only $2.67 \%$ had received education up to the graduate level. This was shown in Figure 2.

Among the selected sample, $28.00 \%$ were addicted to smoking whereas $11.33 \%$ were using alcohol. This was depicted in Table 2. The higher tobacco use in the present study should be a cause of concern. Tobacco habits take shape in adolescence and early adulthood, and tend to continue into old age.

Table 3 show distribution of participants according to the type of family. Among that $74.67 \%$ were nuclear families and $25.33 \%$ were joint families. In a joint family system, the elderly have more interactions with people at home. These social interactions are experienced less in a nuclear family system.

Table 4 show distribution of participants according to type of dietary pattern. Among that $79.33 \%$ were having mixed dietary patterns, $14.00 \%$ were vegetarian and $6.67 \%$ were non-vegetarian.

Among the total study subjects recruited depicted in Figure 3, (35.33\%) of study participants were complained of decreased vision (35.33\%), followed by Musculoskeletal problems $(13.33 \%)$, hearing problems $(12.00 \%)$, urinary problems $(8.00 \%)$, diabetes $(6.00 \%)$, weight loss $(4.67 \%)$, dental problems $(4.00 \%)$, COPD (3.33\%), HTN $(3.00 \%)$ asthma and anaemia with $(2.67 \%)$ each, fatty liver and cancer with $(2.00 \%)$ each and Ischemic heart disease $(0.67 \%)$ in subjects.

Table 5 shows the distribution of visual impairment in geriatric patients. Among that, $15.09 \%$ were having diabetic retinopathy, $10.66 \%$ patients were having age related macular degeneration. $8 \%$ have presbyopia, $4.66 \%$ have glaucoma and $6.66 \%$ have cataract.

Table 6 explains musculoskeletal problems of elderly. Among the participants, 30\% were having arthritis, 25\% were affected by lower back ache, $20 \%$ were affected by osteoporosis, $15 \%$ of patients had fracture and $10 \%$ of patients were with osteoarthritis. This can be explained due to the decreased bone density which occurs as a result of ageing process.

Figure 4 depicts respiratory problem among geriatric population where, $55.55 \%$ were asthma patients and $44.44 \%$ of the population were with chronic obstructive pulmonary disease. 
Table 7 indicates lifestyle diseases in geriatric population. Among participants, $6 \%$ of the patients were with diabetes mellitus, $3 \%$ were with hypertension, $2 \%$ of the participants were with cancer and $0.67 \%$ of participants were having heart disease.

Table 8 represents ENT problems in elderly population. Among participants $12 \%$ were with hearing impairment. This can be correlated due to increased age, which occurs gradually as a person gets older.

Present study shows that $35.33 \%$ of elderly persons were suffering from visual impairment. Shah viral R et al. (2012) found 55.42\% suffering from visual defects 9 . Maroof M et al. (2016) reported that $79.6 \%$ of cataract among elderly, which is similar to the findings of the present study ${ }^{10}$.

In this study, $13.33 \%$ of elderly population have complaints of arthritis. Similarly, Padda AS et al. reported in their study in urban and rural areas of Amritsar found that most common diseases were musculoskeletal $(60.60 \%)$, cataract or visual impairment (54.01\%), caries teeth (21.91\%). Other morbidities were hypertension $(16.6 \%)$, chronic bronchitis $(14.04 \%)$ and asthma $(12.61 \%)^{8}$.

$12.00 \%$ of elderly persons reported hearing problems in this study. Padda AS et al. (1998) his study in Amritsar reported that deafness was found among $3.58 \%$ of the aged persons ${ }^{11}$.

In a study carried out by Manjunath F.V et al it was observed that most commonly complaint of elderly persons was Decreased vision, followed by Hypertension, Insomnia , Diabetes mellitus, Pain in the joints , Micturition problems, Numbness , Pulmonary Koch's , hypothyroid on treatment \& cerebrovascular accident \& COPD , heart disease , cataract , osteoporosis , malignancy and hearing defect 12 .

Thakur R.P et al (2013) in their study showed that the prevalence of visual impairment $(83.29 \%)$ was highest followed by hearing impairment (63.1\%), depression, anaemia, arthritis etc. No statistically significant difference was reported in the prevalence of visual impairment, hearing impairment, hypertension, cataract in both rural and urban areas whereas statistically significant difference was reported in the geriatric population with depression (urban $>$ rural), arthritis (rural > urban), anaemia (rural > urban), diabetes (urban $>$ rural) ${ }^{13}$.

\section{CONCLUSION:}

The study highlights the common health problems the elderly face today. In this study, it was found that the most prevalent health problem among geriatrics was vision impairment followed by arthritis and hearing impairment. The most common causes of vision loss were cataract and diabetic retinopathy. Most of them have undergone cataract surgery. High prevalence of diabetes is reported in economically and epidemiologically advanced states such as Tamil Nadu and Kerala. Diabetic retinopathy is also a leading cause of blindness in elderly. Most of the elderly were affected by osteoarthritis and commonly affected in weight bearing joints. Age related hearing loss is another common health problem among elderly.

This study shows that the quality of health care services to the geriatric population in this area must be improved in order to reduce the burden of diseases and disabilities. The periodic health check-up of the elderly will reduce the morbid sufferings and further deterioration of the already existing conditions. To improve the health status of the elderly various health schemes, policies and programs can be designed based on the study findings. Regular screening and frequent health check-ups should be conducted regularly to lessen morbidity. Day care centres should be started where the old can meet and mingle with their peers and spend their time in a socially meaningful manner. The findings of this study may help the government and private agencies to tackle the problem of all kinds and made ageing a more charming choice and healthy routine.

\section{ACKNOWLEDGEMENT:}

The authors of this article would like to thank everyone responsible for the commencement and completion of this project and everyone who provided information and participated in this study.

\section{Funding: No funding sources}

Conflict of Interest: Authors report no conflict of interest in publishing this research work.

Ethical consideration: The ethical approval to conduct the study was obtained from the Ethical Review Committee. Written consents were obtained from each participant.

\section{REFERENCES:}

1. Hala MS, Safaa A, Sayed S. Comparative study between elderly with medical problems living in dwelling houses and with families in Banha City. Menoufia Med. J. 2017; 30:44-50

2. Brahmbhatt N, Shah TS. A cross-sectional study of health and psychosocial problems among elderly people living in old-age homes of Ahmedabad and Gandhinagar districts, Gujarat, India Int J Med Sci Public Health.2019; 8(11):944-950.

3. Sidik SM, Rampal L, Afifi M. Physical and Mental Health Problems of the Elderly in a Rural Community of Sepang, Selangor. Malays J Med Sci.2004; 11(1):52-59.

4. Jaiganesh D, Prasad K. N, Janaki M. Cross Sectional Study on Health Problems among Elderly inmates of Old age Homes in Urban areas of Chennai, India. ISSN 2277-2812 E-ISSN 2249 8109, 2013; 9(1):96-99.

5. https://vitalrecord.tamhsc.edu. 10 common elderly health issues.

6. https://anvayaa.com. The importance of recreational activities for the elderly.

7. Lena A, Ashok K, Padma M, Kamath V, Kamath A. Health and social problems of the elderly: A cross-sectional study in Udupi Taluk, Karnataka. Indian journal of community medicine: official publication of Indian Association of Preventive \& Social Medicine. 2009 Apr; 34(2):131.

8. Kulothungan K, Tamilarasan M, Britto DR, Sriranganathan T, Sri Andal V. Physical health problems among the geriatric population in Perambalur municipality, Tamil Nadu: a community-based cross-sectional study. Int J Community Med Public Health.2018; 5(12):5235-5241.

9. Shah Viral R, Naresh RM, Kalpesh G, Sudha Y. Health Problems in Geriatrics- a Cross Sectional Study. J Pharm Biomed Sci. 2012; 20(16).

10. Maroof M, Ahmad A, Khalique N, Ansari MA.Health Problem Pattern among Geriatrics in Aligarh- A Cross Sectional Study. Natl J Integr ResMed. 2016; 7(2):61-65.

11. Padda AS, Mohan V, Singh J, Deepti SS, Singh G, Dhillon HS. Health Profile of Aged Persons in Urban and Rural Field Practice Areas of Medical College, Amritsar. Indian J Com Med. 1998; 23:72-76.

12. Manjunath FV, Girish I, Tarini N. Health problems of the elderly in Imphal District, Manipur: A cross sectional study. Ann Geriatr Med Res.2018; 5(1):21-24.

13. Thakur RP, Banerjee A, Nikumb VB. Health Problems among the Elderly: A Cross-Sectional Study. Ann Med Health Sci Res.2013; 3(1):19-25. 